\title{
Longterm effects of problem-based learning: a comparison of competencies acquired by graduates of a problem-based and a conventional medical school
}

Henk G Schmidt, Lyanda Vermeulen \& Henk T van der Molen

BACKGROUND Problem-based learning (PBL) as an approach to the instruction of medical students has attracted much attention in recent years. However, its effect on the performance of its graduates is the subject of considerable debate. This article presents data from a large-scale study among graduates of a problem-based medical school and those of a conventional medical school to contribute to this discussion.

PURPOSE To study the longterm effects of problembased medical training on the professional competencies of graduates.

METHODS A questionnaire was sent to all graduates since 1980 of a problem-based and a conventional medical school. Participants were requested to rate themselves on 18 professional competencies derived from the literature.

RESULTS The graduates of the PBL school scored higher on 14 of 18 professional competencies.

Graduates of the problem-based school rated themselves as having much better interpersonal skills, better competencies in problem solving, self-directed learning and information gathering, and somewhat better task-supporting skills, such as the ability to work and plan efficiently. There were no sizeable differences with regard to general academic competencies, such as conducting research or writing a paper. Graduates from the conventional school rated themselves as having slightly more medical know-

Department of Psychology, University of Rotterdam, Rotterdam, The Netherlands

Correspondence: Henk G Schmidt, Burgemeester Oudlaan 50, Rotterdam 3062 PA, The Netherlands. Tel: 003110408 9648;

Fax: 003110408 9009; E-mail: Schmidt@fsw.eur.nl ledge. The findings were shown to be valid and robust against possible response bias.

CONCLUSION The findings suggest that PBL not only affects the typical PBL-related competencies in the interpersonal and cognitive domains, but also the more general work-related skills that are deemed important for success in professional practice.

KEYWORDS humans; male; female; adult; comparative study; *problem-based learning; clinical competence/ standards; education, medical, undergraduate $/ *$ methods; *attitude of health personnel; *physicians; professional practice/*standards; interprofessional relations; interpersonal relations; Netherlands.

Medical Education 2006; 40: 562-567 doi:10.1111/j.1365-2929.2006.02483.x

\section{INTRODUCTION}

Those who advocate problem-based learning (PBL) as an approach to learning and instruction articulate high expectations of the professional competencies of the graduates produced by such programmes. Students graduating from problem-based medical schools are, for instance, expected to be more skilled in interpersonal communication, ${ }^{1}$ are thought to be better problem-solvers ${ }^{2}$ and to be better prepared for self-directed, lifelong learning. ${ }^{3}$ These expectations are based on the particular characteristics of PBL: students collaborate in small groups, their learning is centred on problems relevant to their domain of study, and they spend much time on self-directed learning. The assumption here is that these activities 


\section{Overview}

\section{What is already known on this subject}

Small-scale studies have suggested that graduates of problem-based medical schools have better interpersonal competencies, positively affecting their interactions with patients.

\section{What this study adds}

Problem-based learning not only affects the level of interpersonal competence of graduates but also seems to influence cognitive skills such as problem solving and task-directed skills such as the ability to work more efficiently.

\section{Suggestions for further research}

The method used in this study was self-rating. Although the findings appear to be consistent with what we know from other studies, there is a need for cross-validation using different methods.

enable students to practise the above-mentioned professional skills while still at university. Graduates of PBL curricula should therefore be better prepared to respond to the challenges of professional practice than graduates of conventional curricula.

The empirical evidence actually supporting these expectations is presently, however, rather limited, in particular because many relevant competencies, such as the skills required to work in a team, are hard to measure and require extended observation periods. In addition, comparing the effects of treatments that extend over several years and do not allow for much experimental control is fraught with difficulties. ${ }^{4,5}$

Consequently, our knowledge of how well graduates of problem-based medical schools perform in professional practice can be summarised in a single paragraph. Firstly, graduates of problem-based medical schools feel better prepared for professional practice than their counterparts from conventional schools. ${ }^{6}$ Secondly, they think that they are able to communicate with their patients in a better way. ${ }^{1}$ Woodward and McAuley at McMaster University in

Canada demonstrated that supervisors characterise graduates from that problem-based school as better communicators with patients. ${ }^{7}$ Such an outcome was also suggested by a recent study at Harvard University: graduates of its PBL track rated their preparation to practise medicine in a humane fashion more highly than did graduates of its conventional track and expressed more confidence in their ability to manage patients with psychosocial problems. ${ }^{8}$ Finally, according to another study, graduates of PBL curricula are better self-directed learners. ${ }^{9}$ However, others have failed to find such differences. ${ }^{10,11}$

Recently, a study among graduates of a problembased medical school suggested that the effects of PBL are largely confined to the interpersonal skills domain: team work, running meetings and helping colleagues, and to cognitive skills typically emphasised by PBL, such as problem solving and selfdirectedness. ${ }^{12}$ However, this study did not include a control group trained at a conventional medical school. To remedy this shortcoming, we conducted a study on graduates of a problem-based school and graduates of a conventional medical school. These graduates were asked to rate themselves on 18 professional competencies assumed to be important to the practice of medicine. These competencies are summarised in Table 1.

Table 1 Average self-ratings of graduates of a problem-based and a conventional medical curriculum on 18 profession-related competencies (standard deviations in brackets). Differences between means $\geq 0.10$ are all statistically significant at the 0.01 level

1 Problem-solving skills

2 Collaboration skills

3 Possession of profession-relevant

knowledge

4 Interpersonal skills

5 Skills relevant to running meetings

(e.g. chairing a meeting)

6 Writing reports or articles

7 Paper presentation skills

8 Research skills

9 Self-directed learning skills

10 Use of information resources

11. Professional skills (such as physical examination)

12. Producing new ideas for
doing one's work in a better way

13 Helping colleagues

14 Productivity

15 Ability to work independently 16 Planning skills

17 Efficiency, time management

18 Ability to work under pressure

$$
\begin{aligned}
& \text { PBL } \\
& \text { curriculum curriculum }
\end{aligned}
$$




\section{METHODS}

\section{Participants}

Participants were 820 graduates of a problem-based medical school in the Netherlands (418 women, 402 men). These graduates represented a $39 \%$ response rate of the total population of 2081 doctors who have graduated from this school since its first batch received their degrees in 1980 . Their average age was 33.57 years and the average length of time since graduation was 8.49 years. As a comparison group, 621 graduates of a conventional medical school were included (324 women, 297 men). The latter group represented a response rate of $19 \%$ of the 3268 doctors who have graduated from this school since 1980. Their average age was 36.20 years and the average length of time since graduation was 9.91 years. Both groups were reasonably similar in terms of gender, age and experience. Inspection of alumni records kept at both medical schools revealed that both groups can be considered representative of their respective populations. For instance, the conventional school's non-responders were on average 35.12 years old and $49.9 \%$ of them were male. Admission criteria for both schools were similar. In fact, in the Netherlands admission to medical school is dealt with at the national level, employing a weighted lottery procedure based on achievement on a national entrance examination. This procedure (inadvertently) results in groups of students in different schools who are quite similar in terms of past performance, age, gender and motivation for studying medicine. (The overall difference in response rate between the 2 groups - 39\% versus $19 \%$ - and its possible implications for the findings will be dealt with in the Discussion section.) The problembased school emphasised problem solving, smallgroup work and self-directed learning, whereas the learning in the conventional school was largely lecture-based.

\section{Instrument and procedure}

In the spring of 1999 all alumni of the PBL curriculum received a questionnaire inquiring about their current perspectives on the quality of their training. Among other items, they were asked to rate themselves on the 18 professionally relevant skills displayed in Table 1 . The list of competencies included was based on an analysis of 3 reports describing the general skills necessary for professional practice in medicine. ${ }^{13-15}$ The graduates' task was to compare themselves with colleagues they knew, who had been trained at another school, and to indicate on a 5-point scale, provided with each of the 18 skills, whether they considered themselves much less competent, less competent, equally competent, more competent, or much more competent than these colleagues. In the spring of 2004 all alumni who had graduated from the conventional school between 1980 and 2003 were sent the same questionnaire.

\section{Statistical analysis}

For each of the competencies and for both the problem-based and the conventional curriculum average ratings were computed. Reliabilities for the instrument as a whole were computed to assess measurement precision. Differences between the 2 groups were tested employing 1-way ANOva. In addition, using AMOs Version 5.0, a confirmatory factor analysis was conducted to test whether subscales could be distinguished. ${ }^{16}$

\section{RESULTS}

The alpha reliability of the items displayed in Table 1 is 0.82 , indicating good measurement precision. Table 1 contains the results of the comparisons.

Graduates of the problem-based school rated themselves more highly not only on the competencies usually associated with PBL, such as skills for collaborating with peers or problem-solving skills, but also on many of the other work-related skills. In total, they rated themselves more highly on 14 of 18 competencies. Graduates of the conventional school rated themselves more highly on the possession of profession-relevant knowledge and writing skills. There were no differences for productivity and ability to work under pressure. The reader should, however, bear in mind that, with large sample sizes such as those found in the present study, differences as small as 0.10 are already statistically significant. Therefore, the results displayed in Table 1, although informative, make it difficult to interpret trends behind the data. To further clarify our findings, the data were aggregated into 4 indices:

1 interpersonal competencies, representing an average score on items pertaining to the ability to work in a team, interpersonal skills, and skills required for running meetings;

2 PBL-related, cognitive competencies such as: problem solving, self-directed learning and information gathering; 
3 general academic competencies such as: writing reports, presenting papers and doing research, and

4 task-supporting competencies such as: producing new ideas, helping colleagues, being productive, being able to work independently, planning one's work adequately, being efficient, and being able to work under pressure.

Although these categories are not mutually exclusive, they provide a more succinct picture of the effects of curricula on graduate performance. To test whether such grouping of variables would be reliable, a confirmatory factor analysis was conducted on the proposed 4-factor structure. ${ }^{16}$ The results of this structural equation modelling attempt were:

$\chi^{2}=426.54$, d.f. $=67, P<0.01, \chi^{2} /$ d.f. $=6.37, \mathrm{CFI}$ (comparative fit index) $=0.95$ and RMSEA (root mean square error of approximation) $=0.06$, indicating that the proposed 4-factor structure comes close to fit with the empirical findings. Table 2 contains the average self-ratings of both groups on these 4 indices of professional competence.

The difference between the graduates of the PBL curriculum and those of the conventional curriculum seems to be particularly large with regard to skills in the domain of interpersonal relations, such as the ability to work in a team, interpersonal skills, and skills required for running meetings:

$F(1,1436)=676,43, M S E=0.26, P<0.01$. In this domain, the mean difference was 0.70 , representing an effect size (ES) equal to 1.30, usually considered a large effect. ${ }^{17}$ This finding is in general agreement with other studies in this area. ${ }^{1,6,7,18}$ Somewhat smaller are the effects of PBL on problem solving, self-directed learning and information gathering skills: $F(1,1436)=247.89, M S E=0.25, P<0.01$. Here the average difference was 0.42 , representing an $\mathrm{ES}=0.78$. This value is generally considered a medium to large effect (effects $\geq 0.80$ are considered

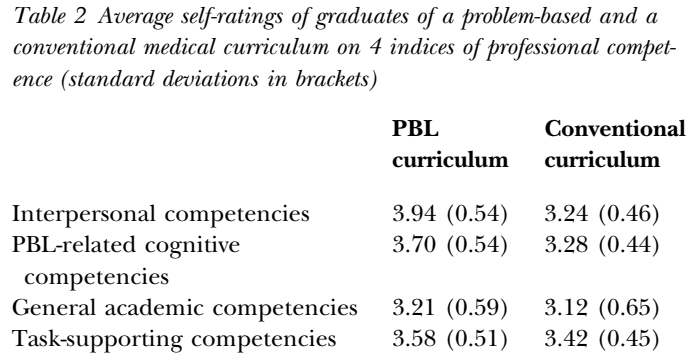

large). Relatively small was the effect with regard to the general academic skills such as report writing, doing research and presenting papers: $F(1,1430)=6.49, M S E=0.38, P<0.05$. Here the average difference was 0.09 , representing a marginal $\mathrm{ES}=0.14$. Finally, for task-supporting competencies, such as productivity, helping colleagues, ability to work independently, planning skills, efficiency and ability to work under pressure, the results were as follows: $F(1,1433)=35.16, M S E=0.23, P<0.01$, $\mathrm{ES}=0.31$. This effect is small but it is nevertheless not without meaning. Statistically, such difference implies that both populations from which the samples were drawn overlap for about $75 \%$ of items; they do not, however, overlap for a sizeable $25 \%$. It seems that PBL, in the perception of its graduates, not only affects the typical PBL-related competencies in the interpersonal and cognitive domains but also the more general work-related skills that are deemed important for success in professional practice.

\section{DISCUSSION}

Of course, surveys of the kind reported here allow for control over the data to a lesser extent than true experiments. Therefore, there may be sources of differences between the groups involved that were not accounted for. We will discuss some of them here.

A first possible source of error concerns the validity of the ratings. To what extent do these self-observations reported here reflect real differences in professional practice? The reader is reminded that each graduate was asked to compare his or her own performance with those of colleagues they knew not to have been trained at the same medical school. A problem with the interpretation of such ratings is, as we have argued elsewhere, ${ }^{12}$ that observers may have overestimated their own competencies, or underestimated those of others, or both. It is, however, possible to check the validity of the self-ratings against other findings reported in the literature. From previous research it is known, for instance, that medical students trained at the particular problem-based school tend not to have more medical knowledge than students trained at conventional schools. ${ }^{19,20}$ In fact, the graduates in our problem-based sample rated themselves slightly lower on this variable than did those from the conventional school. Secondly, the fact that PBL graduates consider themselves as better skilled in the interpersonal domain is corroborated in 2 studies using independent judges: graduates of the PBL schools studied did actually display better interpersonal skills. ${ }^{7,21}$ Thirdly, there is 
no reason to believe that the report writing, presentation and research skills of the graduates of the PBL curriculum are more advanced than those of the conventional school, because the particular PBL curriculum does not put any more emphasis on these topics. Again this reality is reflected in the ratings: PBL graduates rated themselves only marginally better on these general academic skills (mainly because they consider themselves better at presenting papers). From this we conclude that our data do not merely echo the idiosyncratic convictions held by the subjects involved in our study, but reflect true behavioural differences among the samples studied.

A second possible source of error relates to the fact that the data from the graduates of the conventional school were collected 5 years after the data from the PBL group had been collected. It may be possible that more recent classes for some reason or other rated themselves less positively than earlier classes, contributing to the differences between the 2 groups. However, a within-group comparison between the conventional school's classes that graduated before 2000 and more recently graduated classes displayed only 1 significant difference: the younger group rated itself significantly lower on task-supporting competencies: $F(1,620)=4.48, M S E=0.20, P<0.05$. On all other variables, the more recently graduated group rated itself slightly, but not significantly, lower than the older group. These differences are, however, so small that removing this group from the data does not in any way nullify our findings.

A third source of possible invalidation is response bias. The response to the questionnaire was around $40 \%$ for the PBL-trained graduates and $20 \%$ for the graduates of the conventional school; hence, the response of the PBL group was much larger than the 20-25\% typically found in large-scale, mail-based surveys. ${ }^{22}$ To study the possible effects of differential response rates on the findings, several sensitivity analyses were conducted. ${ }^{23}$ The questions to be answered by such analyses are: To what extent are the findings sensitive to the specific samples we studied? Would the results be different if we had been able to draw different samples? In the first sensitivity analysis we increased the sample size of the conventional school with 654 imaginary graduates (an additional $20 \%$, to match the PBL group's response rate), on the assumption that, if these graduates had been included, they would have scored no differently to the PBL group. This analysis essentially cuts the $F$-values resulting from the ANOvas in half. As some of the original findings had large effect sizes, only the difference with regard to general academic competencies became statistically insignificant, suggesting that the original findings are quite robust to sampling errors due to possible response bias.

In 2 further analyses we reduced the size of the PBL sample to $19 \%$ of its population (to match the conventional group). First, we removed the highest scoring individuals on the item pertaining to the possession of profession-relevant knowledge. In the second analysis, we did the same for the highest scoring individuals on the general academic competencies measure. The assumption here is that, in the PBL sample, there may be a group that would generally tend to be more positive about the effects of their training and therefore rate their abilities more highly. By identifying this group and removing them from the analyses, the remaining sample would provide less biased estimates of the remaining variables. However, removing the 421 highest scoring participants of the PBL group left the differences between the PBL group and the conventional group on interpersonal, cognitive and task-supporting competencies largely intact, again demonstrating the robustness of the findings against possible response bias.

\section{CONCLUSION}

This study documents pervasive effects of PBL on the professional competencies of its graduates. Graduates of the problem-based school considered themselves to have much better interpersonal skills, better competencies in problem solving, self-directed learning and information gathering, and better tasksupporting skills, such as the ability to work and plan efficiently. The findings suggest that PBL not only affects the typical PBL-related competencies in the interpersonal and cognitive domains, but also the more general work-related skills that are deemed important for success in professional practice. These findings turned out to be robust against possible response bias. In addition, the response patterns, and their agreement with findings from smaller-scale observational studies, suggested that the findings do not simply reflect the idiosyncratic beliefs of the participants but represent valid observations of themselves and others in professionally relevant situations. However, as our findings extend beyond what others have found, there is a definite need for further corroboration.

One intriguing finding is the difference in response rates between the graduates of the PBL school and those of the conventional school. Both schools were 
established around 1970 and no obvious differences exist among the students who have populated them. A reasonable assumption therefore is that the PBL approach itself inspires greater commitment to the training institute on the part of its students, which manifests in readier willingness to respond to surveys such as that used in this study. Further research is necessary here.

Contributors: HGS and LV designed the study. All authors designed the analysis and HGS and LV analysed the data. HGS wrote the first draft of the paper and all authors contributed to further drafts.

Acknowledgement: the authors thank Dr Geoffrey Norman, McMaster University, for his suggestion that sensitivity analysis should be conducted.

Funding: University Boards of Erasmus University in the Netherlands and Maastricht University.

Conflicts of interest: none.

Ethical approval: the authors state that ethical approval was not applicable.

\section{REFERENCES}

1 Santos Gomez L, Kalishman S, Rezler AG et al. Residency performance of graduates from a problem-based and a conventional curriculum. Med Educ 1990;24(4):366-75.

2 Barrows HS, Tamblyn RM. Problem-Based Learning. New York: Springer Publishing 1980.

3 Peng WW. Self-directed learning: a matched control trial. Teach Learn Med 1989;1:78-81.

4 Albanese MA, Mitchell S. Problem-based learning: a review of literature on its outcomes and implementation issues. Acad Med 1993;68(1):52-81.

5 Schmidt HG, Dauphinee WD, Patel VL. Comparing the effects of problem-based and conventional curricula in an international sample. JMed Educ 1987;62(4):305-15.

6 Mennin SP, Kalishman S, Friedman M, Pathak D, Snyder J. A survey of graduates in practice from the University of New Mexico's conventional and community-oriented, problem-based tracks. Acad Med 1996;71(10):1079-89.

7 Woodward CA, McAuley RG. Can the academic background of medical graduates be detected during internship? CMAJ 1983;129:567-9.

8 Peters AS, Greenberger-Rosovsky R, Crowder C, Block $\mathrm{SD}$, Moore GT. Longterm outcomes of the new pathway programme at Harvard medical school: a randomised controlled trial. Acad Med 2000;75(5):470-9.
9 Shin JH, Haynes RB, Johnston ME. Effect of problembased, self-directed undergraduate education on lifelong learning. CMAJ 1993;148(6):969-76.

10 Tolnai S. Continuing medical education and career choice among graduates of problem-based and traditional curricula. Med Educ 1991;25(5):414-20.

11 Tolnai S. Lifelong learning habits of physicians trained at an innovative medical school and a more traditional one. Acad Med 1991;66(7):425-6.

12 Schmidt HG, Van der Molen HM. Self-reported competency ratings of graduates of a problem-based medical curriculum. Acad Med 2001;76:466-8.

13 Association American of Medical Colleges. General Professional Education of the Physician (GPEP), Physicians for the Twenty-First Century. The GPEP Report. Washington, DC: American Association of Medical Colleges 1984.

14 Association American of Medical Colleges. Learning Objectives for Medical Student Education. Guidelines for Medical Schools. Washington, DC: American Association of Medical Colleges 1998.

15 General Medical Council. The New Doctor. London: GMC 1997.

16 Arbuckle JL. Amos 5.0 Update to the User's Guide. Chicago: SmallWaters Corporation 2003.

17 Cohen J. Statistical Power Analysis for the Behavioural Sciences. New York: Academic Press 1979.

18 Prince K, van Eijs PW, Boshuizen HP, van der Vleuten CP, Scherpbier AJ. General competencies of problembased learning (PBL) and non-PBL graduates. Med Educ 2005;39(4):394-401.

19 Verwijnen GM, van der Vleuten C, Imbos T. A comparison of an innovative medical school with traditional schools: an analysis in the cognitive domain. In: Nooman Z, Schmidt HG, Ezzat E, eds. Innovation in Medical Education, an Evaluation of its Present Status. New York: Springer Publishing 1990;40-9.

20 van der Vleuten CPM, Schuwirth LWT, Muijtjens AMM, Thoben AJNM, Cohen-Schotanus J, Van Boven CPA. Cross-institutional collaboration in assessment: a case on progress testing. Med Teacher 2004;26(8):719-25.

21 Jones A, McArdle PJ, O’Neill PA. Perceptions of how well graduates are prepared for the role of pre-registration house officer: a comparison of outcomes from a traditional and an integrated PBL curriculum. Med Educ 2002;36(1):16-25.

22 Armstrong JS, Lusk EJ. Return postage in mail surveys: a meta-analysis. Public Opinion Q 1987;51:233-48.

23 Saltelli A, Chan K, Scott EM. Sensitivity Analysis. Hoboken, New Jersey: Wiley 2000.

Received 18 May 2005; editorial comments to authors 19 July 2005; accepted for publication 14 October 2005 